\title{
Photoperiod induction of fertile oestrus and changes in LH and progesterone concentrations in yearling dairy goats (Capra hircus)
}

\author{
R. H. BonDurant, B. J. Darien*, C. J. Munro, G. H. Stabenfeldt and \\ P. Wang
}

Department of Reproduction, School of Veterinary Medicine, University of California, Davis, California 95616, U.S.A.

\begin{abstract}
Summary. Oestrus and ovulation were induced in a group of 19 yearling dairy goats which had been maintained for 70 days on a $19 \mathrm{~h} /$ day photoperiod regimen. Six yearling females, raised under natural photoperiod, served as controls. An intact, light-treated male was introduced to each group 42 days after termination of the artificial lighting. Behavioural, endocrine and kidding observations indicated that 15 of the experimental females (79\%) ovulated within 21-30 days after introduction of the male, that $12(63 \%)$ conceived at the induced ovulation, and that $10(53 \%)$ gave birth to live kids, while none of the controls ovulated during this time. The breeding season was advanced between 60 and 80 days.

In experimental and control nannies there was a brief, small surge $(320 \pm 42$ $\mathrm{pg} / \mathrm{ml}$ ) of plasma progesterone which occurred 19.5 days after introduction of the male and which closely preceded oestrus in the nannies that ovulated and at 25 days in control females.

Ovulatory surges of LH (to $70 \mathrm{ng} / \mathrm{ml}$ plasma) were closely associated with oestrus, and remained above basal levels for $9.0 \pm 0.75 \mathrm{~h}$, in 7 experimental females. Two of 6 control nannies also showed LH surges but they did not ovulate.
\end{abstract}

\section{Introduction}

Attempts to induce fertile oestrus in the dairy goat female during the anoestrous season have primarily involved the use of exogenous progestagens and/or gonadotrophins (Smith, 1955; Stubbings, 1968; Jones \& Knifton, 1971; Corteel, 1975, 1977; Ahmed, Phelps, Foote \& Foote, 1977). While out-of-season pregnancy rates as high as $40-60 \%$ have been attained (Corteel, 1977; Foote, 1979), little attention has been given to the possibility of inducing oestrus by manipulation of the photoperiod, an approach which has been intensively investigated for the ewe (Yeates, 1949; Hafez, 1952; Ducker \& Bowman, 1970; Ducker, 1974; Hunter \& Van Aarde, 1975; Robinson, Fraser \& McHattie, 1975). Anecdotal information regarding the use of various light-altering schedules in commercial goat dairies has been published in the lay literature (Guss, 1977; Osman, 1978; Considine, 1979), but few, if any, controlled observations have been recorded. Furthermore, little work is available regarding the endocrine events surrounding normal oestrus in the goat, e.g. the relationship of the ovulatory LH surge to the onset of oestrus, the duration of the LH surge, and the importance of the role of progesterone in the expression of first oestrus.

This paper reports on behavioural and endocrinological observations in a commercial goat herd in which fertile oestrus was induced in yearling nannies by photoperiod manipulation.

* Present address: c/o Faculty of Veterinary Science, University of Pretoria, Onderstepoort, South Africa. 


\section{Materials and Methods}

The commercial goat herd used in this study is located in Northern California at about $37^{\circ} \mathrm{N}$ latitude. The animals in this study, 20 French Alpine and 6 Toggenburg females, were part of a group of approximately 160 yearling nannies which were placed in a barn $(30 \times 12 \mathrm{~m})$ with free access to outside exercise pens maintained at all times via open doorways; all windows in the barn were also left open, and no attempt was made to force the animals into the covered, lit part of the barn. Mature males were kept in a separately fenced area of the barn within sight of the females. All animals were fed 'free choice' alfalfa hay in the barn.

Beginning 26 January 1978, the barn was exposed to $19 \mathrm{~h}$ of artificial light per $24 \mathrm{~h}$ (Text-fig.1) by means of 10 pairs of $2.4-\mathrm{m}, 40-\mathrm{W}$ fluorescent lamps hung at approximately $2 \mathrm{~m}$ above animal level. An automatic timer turned the lights on at $05: 00 \mathrm{~h}$ and off at $24: 00 \mathrm{~h}$ each day. On 6 April 1978, 70 days after artificial lighting was begun, the timer was turned off, leaving the goats exposed to natural photoperiod. On 28 April, 20 French Alpine yearling females, scheduled by the owner to be penned together, were selected for study and identified with neck tags (Group AP). Six Toggenburg yearling females raised outdoors under natural photoperiod (Group NP) were then brought into the barn to serve as controls. Beginning at this time, all 26 animals were bled by jugular venepuncture twice weekly until introduction of the males.

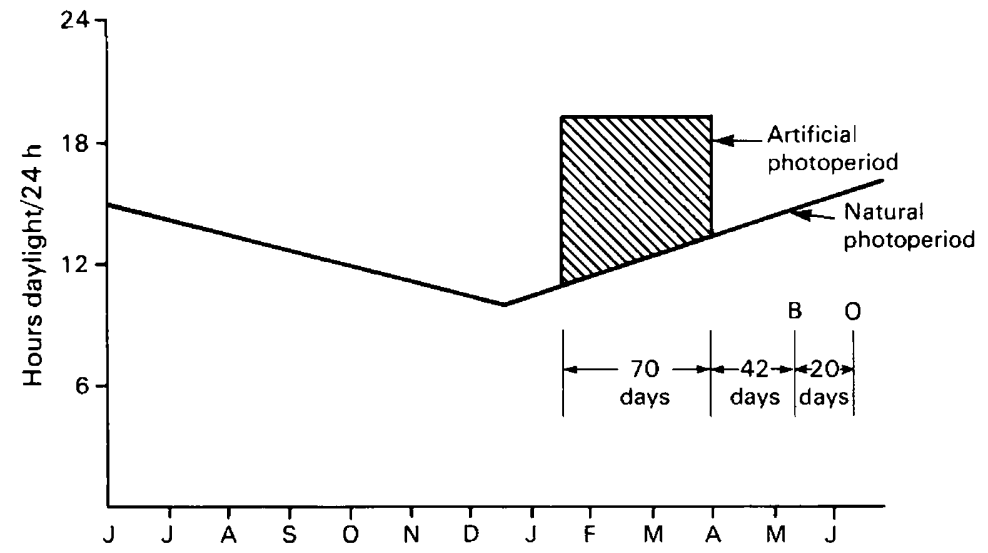

Text-fig. 1. Lighting and management protocol for the 19 nannies in Group AP. B = introduction of the billy goat; $\mathrm{O}=$ first oestrus.

On 18 May, 42 days after termination of artificial lighting, the barn was divided into 8 pens of approximately 20 females each. A single, fertile, light-treated male was introduced into each pen (Text-fig. 1). Males were painted on their briskets with chin-ball marking ink. The 20 pre-selected animals in Group AP and one billy were housed in a single pen, while the 6 Group NP animals ran with unsampled, light-treated females and a light-treated male in a separate pen.

After introduction of the male, all nannies in Groups AP and NP were bled daily at approximately 12:00 h, until oestrus was detected in either group; then all females in that group were bled by venepuncture every $2 \mathrm{~h}$. When approximately half the animals in either group had shown oestrus, the intensive blood sampling was terminated, and twice weekly sampling resumed for approximately 21 days. All samples were collected in evacuated heparinized containers; samples were centrifuged and plasma was immediately frozen in glass vials at $-20^{\circ} \mathrm{C}$.

\section{Hormone assays}

Progesterone. Radioimmunoassay was used to measure progesterone concentrations in all 
daily and twice-weekly samples, and in the 12:00 $\mathrm{h}$ samples during intensive bleeding. The methods of extraction and assay were those described by Shille \& Stabenfeldt (1979); rabbit-derived K45 antiserum to progesterone (K45) was kindly supplied by Dr L.-E. Edqvist (Royal Veterinary College, Uppsala, Sweden). A chromatographic separation step was not used; recovery was about $91 \%$ and the detection limit of the assay was about $80 \mathrm{pg} / \mathrm{ml}$. The interassay coefficient of variation was $16 \%$; the intra-assay precision was $12 \%$ for values of $500-1000$ $\mathrm{pg} / \mathrm{ml}$ and $7 \%$ for $1-20 \mathrm{ng} / \mathrm{ml}$.

$L H$. The radioimmunoassay procedure used in the determination of $\mathrm{LH}$ was essentially the same as the heterologous ovine-ovine system for rats described by Niswender, Midgley, Monroe \& Reichert (1968). The reference standard of ovine LH was LER-1374A and the tracer was LER-1056-C2, both kindly supplied by Dr L. E. Reichert (Albany Medical College, Albany, New York). Rabbit antiserum to ovine LH (GDN No. 15) was supplied by Dr G. D. Niswender (Colorado State University, Fort Collins, Colorado). Ovine anti-rabbit gamma globulin, developed in our laboratory, was added at a dilution of $1: 25$. Each plasma sample $(50 \mu 1$ aliquot) was determined in triplicate, and each concentration of the standard curve in quadruplicate. Under these conditions the working range of the standard curve extended from 0.01 to $2.0 \mathrm{ng} /$ tube, and the minimum detectable concentration of LH in caprine plasma, defined as two standard deviations from the buffer control $\times$ the dilution correction factor (20), was $0.2 \mathrm{ng} / \mathrm{ml}$. Repeated estimates of the LH concentration in pools of goat plasma containing high and low values of LH gave interassay coefficients of variation for the low and high pools of 6.4 and $8.9 \%$, respectively, and an intra-assay coefficient of variation of $11 \cdot 1 \%$. Specificity of the assay was validated by comparison of inhibition curves of serial dilutions of a range of goat plasmas with the ovine-ovine standard curve used in the assay (Text-fig. 2).

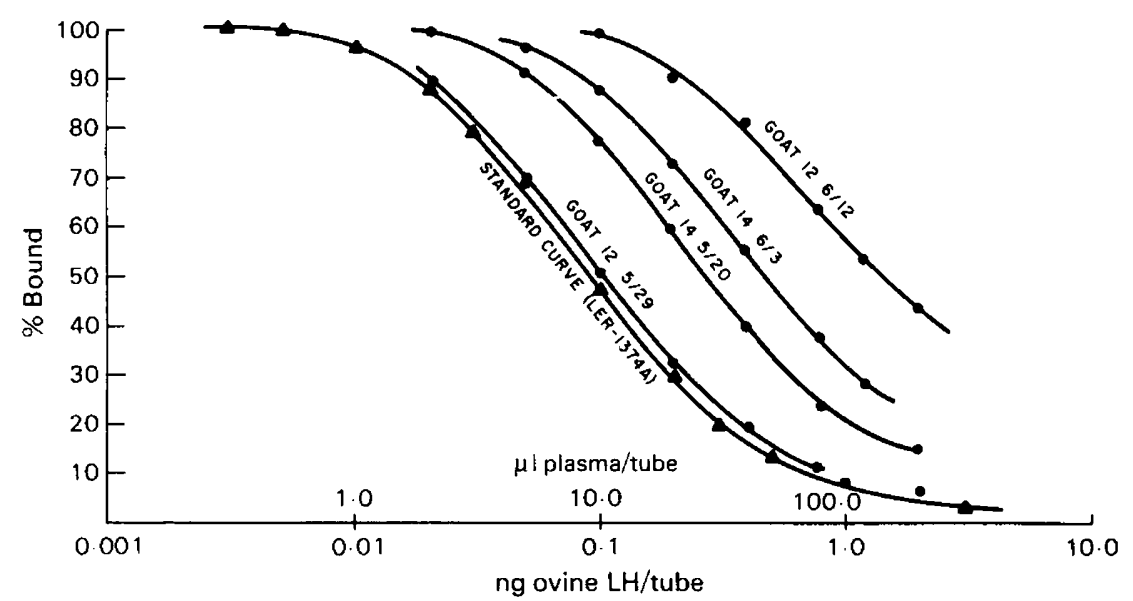

Text-fig. 2. Inhibition curves of goat plasma samples (๑) demonstrating parallelism with standard ovine-ovine curve (A) (see text for details).

Behaviour. Oestrous behaviour was assessed by the presence of rump and tail-head markings on the females, and confirmed by the observation of coitus. Animals showing some light marking of the rump area, but not seen to be mated, were listed only as marked. Before the intensive sampling schedule animals were observed daily for a total of about $1 \mathrm{~h}$, and then at 2-h intervals during intensive sampling $\left(09: 00 \mathrm{~h}\right.$ on 7 June to $11 \mathrm{l}^{\circ} 00 \mathrm{~h}$ on $\left.9 \mathrm{June}\right)$. 


\section{Results}

\section{Oestrus}

One of the Group AP females was killed before the billy was introduced. Of the 19 remaining, $16(84 \%)$ were heavily marked between 7 and 13 June, and for 10 of these (63\%) copulation was also observed. An initial intensive bleeding schedule was elicited by a number of females being lightly marked about 5-6 days before onset of complete sexual receptivity. Of the 6 females in Group NP, only 1 was slightly marked and none was observed mating.

\section{Ovulation}

In Group AP, 15 of the 19 (79\%) females ovulated, as judged by a prolonged, significant rise in plasma progesterone concentrations during the period of study (Jones \& Knifton, 1972; Thorburn \& Schneider, 1972). Of these 15, 14 (93\%) had also been marked, or marked and served; 2 of the 16 marked animals did not ovulate, nor did any of the 6 NP females, as judged by the absence of a normal post-ovulatory progesterone rise (Text-figs 3 and 4 ).

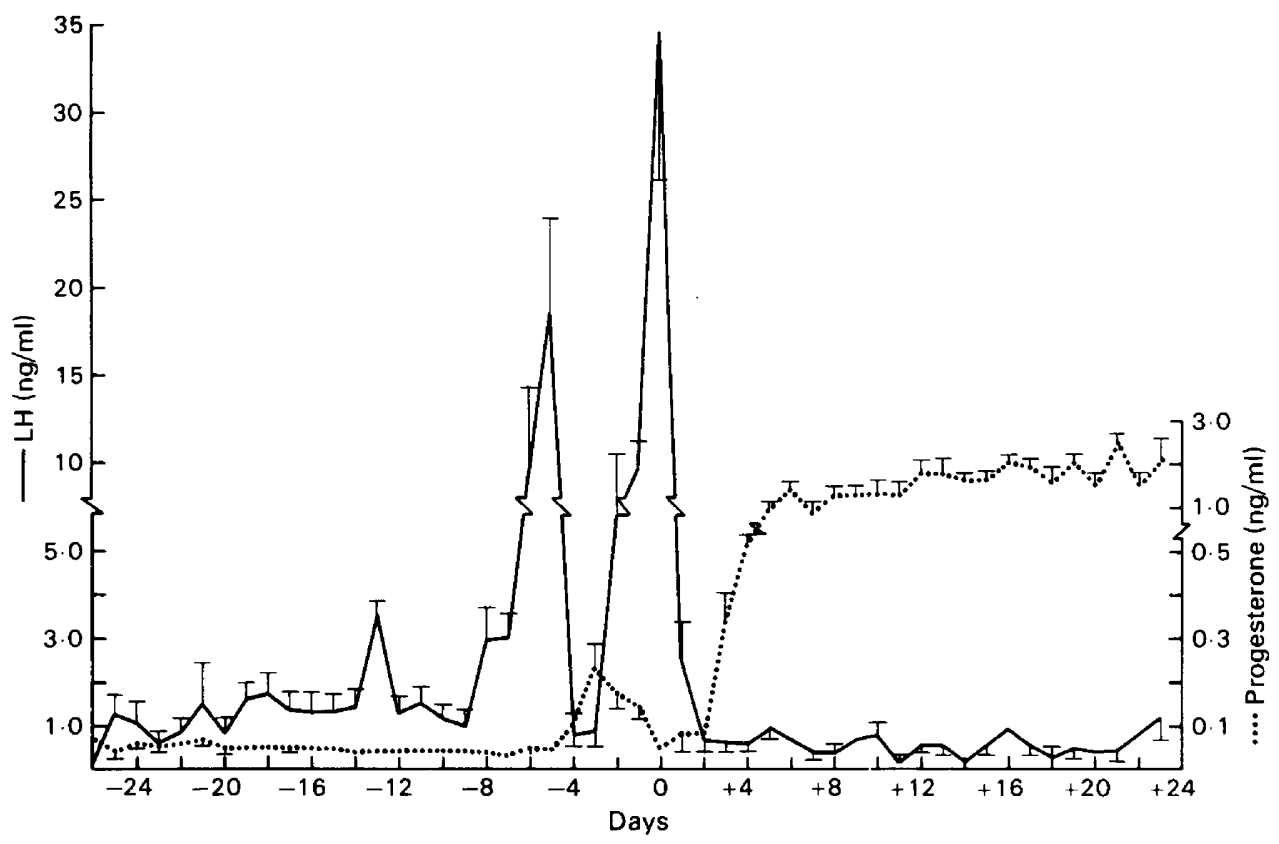

Text-fig. 3. Composite diagram of progesterone $(\cdots)$ and LH $(-)$ concentrations (mean \pm s.e.m.) in plasma of 15 experimental (AP) nannies. Day $0=$ day of observed oestrus $(N=10)$ or estimated oestrus $(\mathrm{N}=5)$.

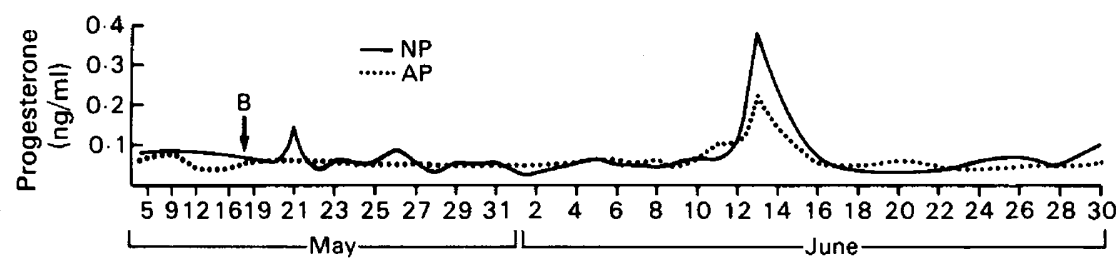

Text-fig. 4. Mean plasma progesterone concentrations in the 4 AP nannies that did not ovulate $(\cdots)$ and in 3 NP females (-). B = billy introduced. 
Pregnancy

Eleven of the 15 AP females that ovulated conceived at the first ovulation, based on parturition dates of mature kids (one nanny aborted normally developed twins at 117 days). Another nanny conceived at a second ovulation 21 days later as judged by extrapolation from kidding data. The 12 nannies gave birth to 6 sets of twins and six singletons. Total conception rate for the 19 females exposed to the lighting regimen was $63 \%$. None of the animals in Group NP had kidded by 7 months after the termination of blood sampling, 1 July 1978.

\section{Progesterone concentrations}

Mean ( \pm s.e.m.) plasma progesterone levels were low in AP nannies $(48 \pm 4 \mathrm{pg} / \mathrm{ml})$ and in $5 / 6 \mathrm{NP}$ females $(41 \pm 2 \mathrm{pg} / \mathrm{ml})$ for the first 16 days after introduction of the male; these values were not significantly different $(P>0 \cdot 1)$. Progesterone concentrations in the 6th NP nanny were $114 \pm 5 \mathrm{pg} / \mathrm{ml}$. There was no difference between the basal progesterone values in AP females that ovulated $(49 \pm 6 \mathrm{pg} / \mathrm{ml})$ and those that failed to ovulate $(54 \pm 6 \mathrm{pg} / \mathrm{ml})$. Progesterone values increased significantly $(P<0.001)$ to give peak values of $320 \pm 42 \mathrm{pg} / \mathrm{ml}$ in the $15 \mathrm{AP}$ animals that ovulated, beginning 17-25 days (mean 19.5 days) after the introduction of the male. A composite of this progesterone surge is shown in Text-fig. 3, along with its relationships to $\mathrm{LH}$ release. A similar progesterone rise occurred slightly later in non-ovulating AP nannies (24-26 days, peak concentration, $300 \pm 119 \mathrm{pg} / \mathrm{ml}$ ) and in $3 / 6 \mathrm{NP}$ animals (24-26 days; $252 \pm 46 \mathrm{pg} / \mathrm{ml}$ ). These peak progesterone concentrations were not different (Text-fig. 4).

The duration of the progesterone surge was $1.9 \pm 0.1,1.3 \pm 0.3$ and $2.0 \pm 0.7$ days for ovulating AP, non-ovulating AP, and NP animals, respectively. One nanny that ovulated was unusual in that progesterone surge concentrations were maintained at greater than baseline values for 5 days. A return to basal concentrations for 2 days was then observed, followed by the ovulatory (luteal) rise in progesterone.

Plasma progesterone levels were determined in 10 animals at 19-22 days after ovulation and before 1 July when the bleeding schedule was ended. Progesterone concentration in the 9 that conceived at first ovulation was $\geq 1410 \mathrm{pg} / \mathrm{ml}$ on Day 20 after oestrus. In the tenth nanny the plasma progesterone concentration was $90 \mathrm{pg} / \mathrm{ml}$ at 19 days after the estimated day of oestrus, but 4 days later (oestrus plus 23 days) progesterone levels rose to $764 \mathrm{pg} / \mathrm{ml}$, suggesting that another cycle had begun.

No significant difference in progesterone levels for Days 19-22 was seen between the 5 nannies of this group that gave birth to singles and the 4 that twinned.

\section{Plasma LH levels}

The surge of $\mathrm{LH}$ preceding the sustained progesterone rise, and associated with oestrus, was considered to be the ovulatory surge. The interval from the introduction of the billy to the ovulatory surge of $\mathrm{LH}$ ranged from 20 to 22 days. The interval from the beginning of the preovulatory progesterone surge averaged $2 \cdot 3$ days (range $1-3$ ).

Data from two goats (Nos 1 and 14) which exhibited two distinct surges of $\mathrm{LH}$ are shown in Text-fig. 5. In both cases, the first peak was followed by a small progesterone rise. This, in turn, was followed by a second LH surge which was associated with oestrus and ovulation. Other LH release patterns for individual animals are shown in Text-fig. 6. For the 7 females that exhibited an ovulatory surge within the 50-h intensive sampling period, the duration of the surge above basal levels was $9.0 \pm 0.75 \mathrm{~h}$. Peak levels were from 40 to $>70 \mathrm{ng} / \mathrm{ml}$. Coitus (oestrus) first

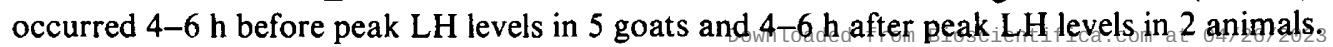




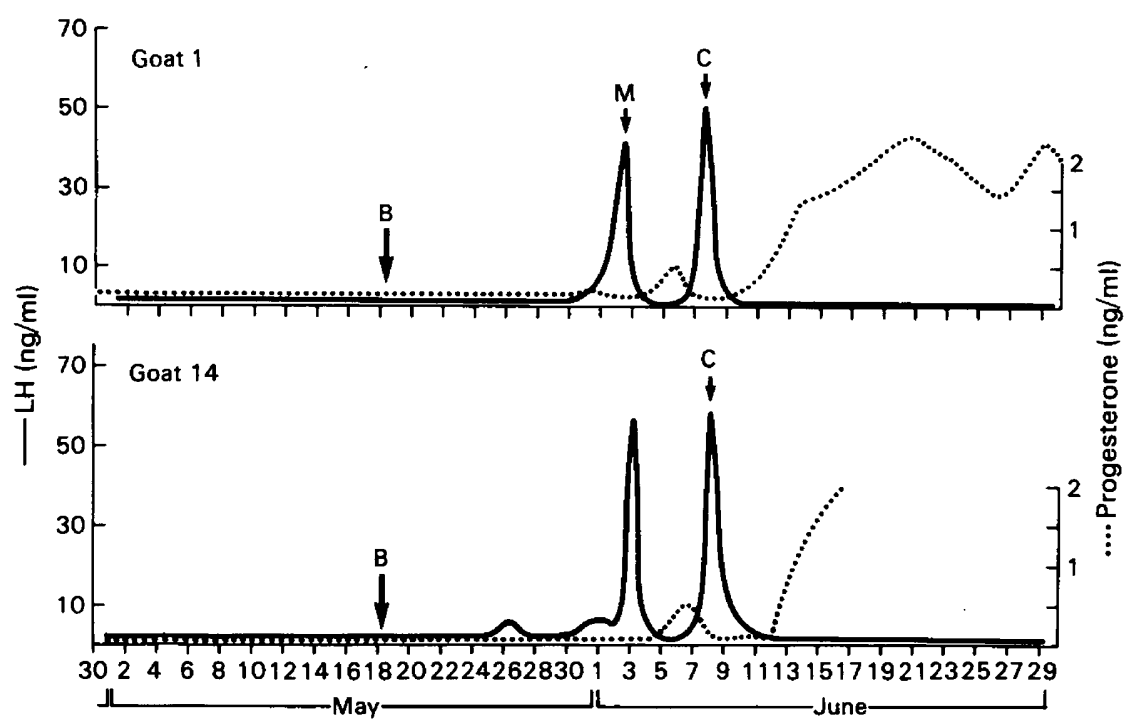

Text-fig. 5. Plasma LH (-) and progesterone (...) concentrations of Goats 1 and 14 showing the occurrence of two distinct surges of LH 5 days apart. $\mathrm{B}=$ billy introduced; $\mathrm{C}=$ coitus; $\mathrm{M}=$ marked.

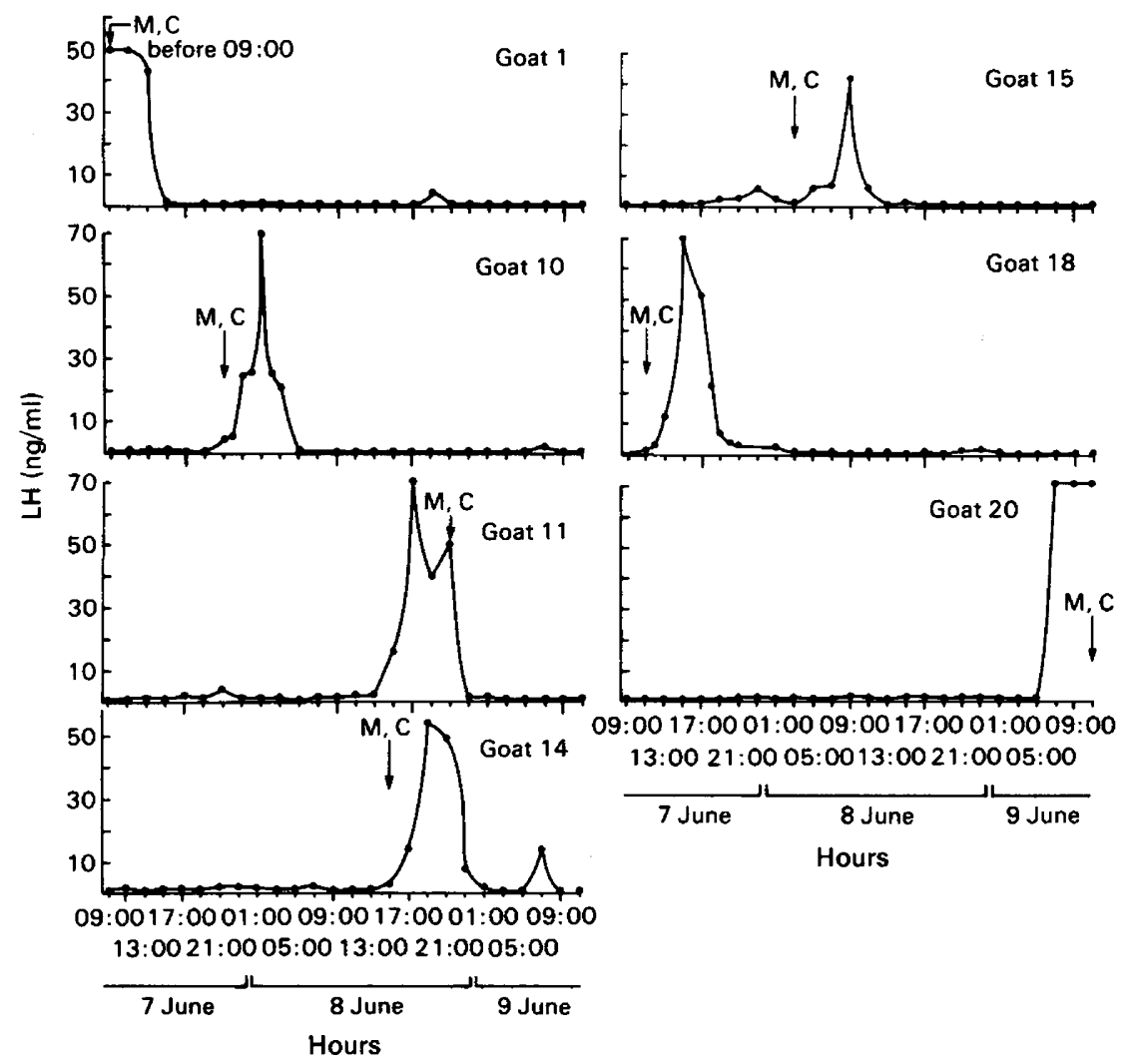

Text-fig. 6. Plasma LH levels in 7 AP nannies exhibiting an ovulatory surge during the 50-h period of intensive sampling (7-9 June). $M=$ marked; $C_{\text {ace }}$ coitus. 
Two goats in Group NP showed marked surges of LH (Text-fig. 7). Goat NP 3 exhibited a 1-day spike of LH on 8 June ( 21 days after the male was introduced) while goat NP 5 showed an apparently sustained LH surge from 7 to 9 June (20-22 days after introduction of the billy). This animal also showed some light markings but no observed coitus. LH levels in the other NP nannies, did not rise above $8-10 \mathrm{ng} / \mathrm{ml}$. However, because none of the controls showed oestrous behaviour, an intensive sampling was not initiated and it is possible that there were some brief LH surges in the controls that were not detectable in the daily samples.

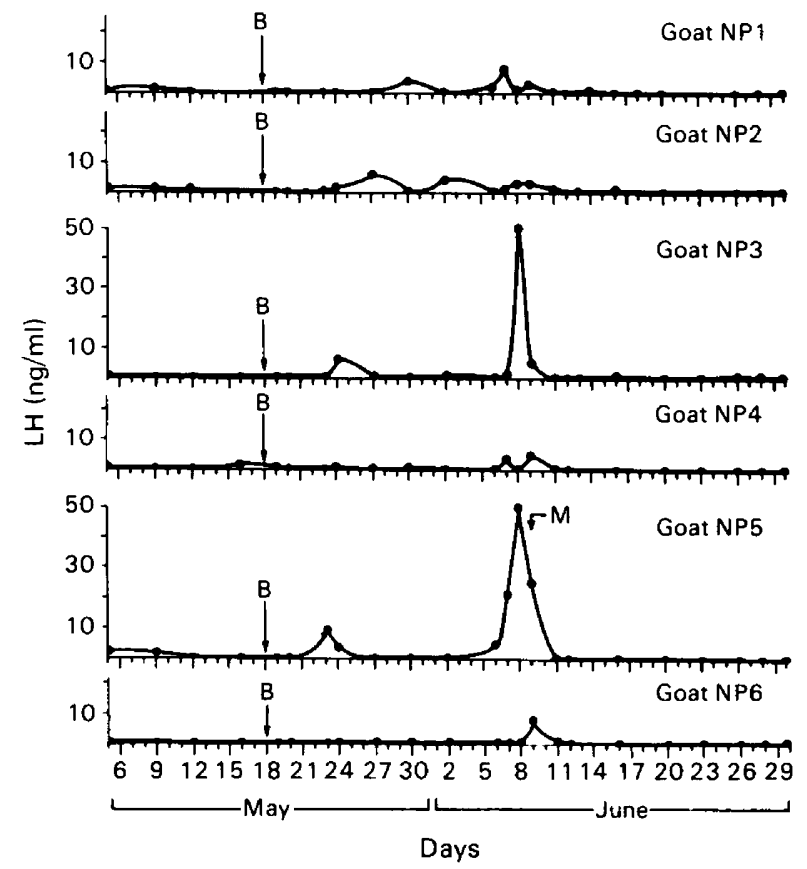

Text-fig. 7. Plasma LH and progesterone levels in control (NP) animals. B = billy introduced; $\mathbf{M}=$ marked slightly.

\section{Discussion}

That oestrus and ovulation can be induced in yearling dairy goats during the time of the traditionally 'deep anoestrus' was clearly shown in this study. Ovulation occurred in the 15 nannies between 8 and 17 June, as judged by LH and/or progesterone values. As the first spontaneous oestrous activity in Alpine and Toggenburg females begins between 15 August and 1 September in this herd, advancement in the onset of the breeding season by $60-80$ days was achieved by the treatment. The induced oestrus (and ovulation) was fertile as judged by an $80 \%$ conception rate in those that ovulated. The number of kids/nanny kidding (1.5) closely approached that of adult goats at this dairy (1.6) and exceeded the $33 \%$ twinning rate reported by Lyngset (1968) in slaughterhouse studies. In addition, expensive 'light-tight' facilities (see Ortavant, 1977) were not required.

Although different breeds were used for control and experimental animals in this report, no basis for breed differences in response is known to exist. Other authors (Phillips, Simmons \& Schott, 1943; Corteel, 1977; Guss, 1977) have indicated that, amongst dairy goat breeds, the Swiss breeds (Alpine, Saanen and Toggenburg) have very similar seasonal breeding limitations 
and oestrous cycle characteristics. Toggenburg females were used as controls for light-treated Alpines in this study, because of a lack of Alpine females exposed only to natural photoperiod. Since both of these breeds begin cyclic ovarian activity at approximately the same time (15 August to 1 September) at the location of this study, it was assumed that Toggenburgs are as sensitive to photoperiod as are Alpines, and can therefore be considered to be adequate controls. It is possible, however, that the difference in ovulatory response to treatment between the two breeds used in this study is a manifestation of differences in breed susceptibility to oestrus induction by either the presence of a male or photoperiod manipulation, or both.

Photoperiod manipulation of female goats may establish conditions necessary for continuous cyclic ovarian activity because 2 nannies had a second oestrous cycle before the end of the experiment (30 June) and one conceived. Corteel (1977) has suggested that hormonal induction of oestrus in goats during the anoestrous season results in one heat period only. Induction of oestrus by photoperiod changes may therefore offer the advantage of repeat breeding for those animals that fail to conceive at the first oestrus.

The occurrence of a small and brief, but significant, rise in plasma progesterone just before oestrus (and ovulation) is similar to that described for the period immediately before oestrus in pubertal beef heifers (Gonzalez-Padilla, Wiltbank \& Niswender, 1975), and in ewes during the transition period immediately before the breeding season (Walton, Cunningham, Temple \& Bowman, 1974; Yuthasastrakosol, Palmer \& Howland, 1975). The ewe, however, does not manifest oestrus with the first ovulation of the breeding season. In direct contrast to the transition-period ewe, the first ovulation in the yearling females in this study was accompanied by oestrus in nearly all animals (14/15). The exact function of the brief, small rise in progesterone is not known, but it may be important for the manifestation of the pubertal oestrus (in goats and cattle) in concert with subsequent follicular growth and oestrogen production, and the ovulatory release of $\mathrm{LH}$.

Males were seen to show interest in the females (lightly marked) about 4-5 days before oestrus was definite. This pro-oestrous-like activity, probably associated with the first major release of $\mathbf{L H}$, occurred in the absence of any detectable steroidal priming. This observation, and the close relationship between ovulatory LH release and the onset of definite oestrus, support the concept of a probable role of LH-RH in the manifestation of oestrus (Pfaff, 1973; Lamorde, 1974; Lemon, Pelletier, Saumande \& Signoret, 1975).

The introduction of a billy into a group of nannies may not only hasten the onset of the breeding season by several days, but can also effectively synchronize such a group (Angora: Shelton, 1960; dairy goats: Ott, Nelson \& Hixon, 1980). The presence of a ram during oestrus will hasten the onset of an LH surge and ovulation in ewes (Lindsay, Cognie, Pelletier \& Signoret, 1975), and Chesworth \& Tait (1974) have shown that introduction of a ram into a group of ewes at the beginning of breeding season stimulates a small, but significant, rise in LH levels within $10 \mathrm{~h}$ of introduction. No such measurements were taken in the goats described here, but the degree of synchrony strongly suggests an effect of the male, but only after sensitization by the change of photoperiod. It is not known what effect, if any, lactation would have on the response to artificial photoperiod, because only yearling animals were used. Corteel (1975) has recommended that hormonal induction of oestrus not be attempted during lactational anoestrus in the goat, but Hunter \& Van Aarde (1975) and Robinson, Fraser, McHattie \& Gill (1975) have indicated a benefit from photoperiod treatment which accelerates the onset of a post-partum oestrus in ewes. Further investigation of these interactions in goats is clearly needed.

We thank Mr Wes Norfeldt for providing the goats for the study and Dr Thomas Farver (Dept of Epidemiology \& Preventive Medicine, University of California, Davis), for providing assistance with statistical analysis of the data. The work was supported in part by a Faculty Research Grant (No. 557016-19900-5), University of California, Davis, California. 


\section{References}

Ahmed, S., Phelps, D.A., Foote, W.D. \& Foote, W.C (1977) Out of season breeding in dairy goats. Proc. Western Section, Am. Soc. of Anim. Sci. 28, 199-201.

Chesworth, J.M. \& Tait, A. (1974) A note on the effect of the presence of rams upon the amount of luteinizing hormone in the blood of ewes. Anim. Prod. 19, $107-110$.

Considine, H. (1979) Breeding season can be regulated with lights. Dairy Goat Journal 57, pp. 3, 30.

Corteel, J.M. (1975) The use of progestagens to control the oestrous cycle of the dairy goat. Annls Biol. anim. Biochim. Biophys. 15, 353-363.

Corteel, J.M. (1977) Management of AI of dairy seasonal goats through oestrus synchronization and early pregnancy diagnosis. Proc. Sheep Industry Development Conference, Suppl. pp. 1-20. Ed. C. Terrill. University of Wisconsin, Madison.

Ducker, M.J. (1974) Effect of artificial daylight changes on the reproductive rate of sheep. Vet. Rec. 95, 96-98.

Ducker, M.J. \& Bowman, J.C. (1970) Photoperiodism in the ewe. Anim. Prod. 12, 513-516.

Foote, W.C. (1979) Hormonal control of reproduction in sheep and goats. In Sheep and Goat Practice Symposium, pp. 44-54. Ed. D. Bailey. Am. Ass. of Sheep and Goat Practitioners, and Office of Extension, College of Veterinary Medicine, Colorado State University, Ft Collins.

Gonzalez-Padilla, E., Wiltbank, J.M. \& Niswender, G.D. (1975) The interrelationship between pituitary, hypothalamic and ovarian hormones. J. Anim. Sci. 40, 1091-1104.

Guss, S. (1977) Management and Diseases of Dairy Goats. Dairy Goat Journal Publishing Corp., Scottsdale, Arizona.

Hafez, E.S.E. (1952) Studies on the breeding season and reproduction of the ewe. J. agric. Sci., Camb. 42, 189-265.

Hunter, G.L. \& Van Aarde, I.M.R. (1975) Influence of age of ewe and photoperiod on the intervals between parturition and first oestrus in lactating and nonlactating ewes at different nutritional levels. $J$. Reprod. Fert. 42, 205-212.

Jones, D.E. \& Knifton, A. (1971) Attempted induction and synchronization of oestrus in goats by the use of progestinated intravaginal pessaries. Vet. Rec. 89, 348-352.

Jones, D.E. \& Knifton, A. (1972) Progesterone concentration in the peripheral plasma of goats during the oestrous cycle. Res. Vet. Sci. 13, 193-195.

Lamorde, A.G. (1974) The effect of synthetic gon adotrophin releasing hormone $(\mathrm{GnRH})$ on quiescent ovaries in prepuberal gilts and lactating sows. Ph.D. thesis, University of California, Davis.

Lemon, M., Pelletier, J., Saumande, J. \& Signoret, J.P. (1975) Peripheral plasma concentrations of progesterone, oestradiol-17 $\alpha$ and luteinizing hormone around oestrus in the cow. J. Reprod. Fert. 42, 137-140.

Lindsay, D.R., Cognie, Y., Pelletier, J. \& Signoret, J.P. (1975) Influence of presence of rams on the timing of ovulation and discharge of LH in ewes. Physiol. Behav. 15, 423-426.
Lyngset, 0. (1968) Studies on reproduction in the goat. III. Functional activity of the ovaries of the goat. Acta vet. scand. 9, 268-276.

Niswender, G.D., Midgley, A.R., Jr, Monroe, S.E. \& Reichert, L.E., Jr (1968) Radioimmunoassay for rat luteinizing hormone with anti-ovine $\mathrm{LH}$ serum and ovine LH ${ }^{131}$ I. Proc. Soc. exp. Biol. Med. 128, $807-811$.

Ortavant, R. (1977) Photoperiodic regulation of reproduction in the sheep. In Management of Reproduction in Sheep and Goats Symposium, pp. 58-71. Ed. C. Terrill. University of Wisconsin, Madison.

Osman, L.H. (1978) He tends two flocks. Hoard's Dairyman 123, 156-157.

Ott, R.S., Nelson, D.R. \& Hixon, J.E. (1980) The effect of presence of the male on initiation of estrous cycle activity of goats. Theriogenology 13, 183-190.

Pfaff, D.W. (1973) Luteinizing hormone releasing factor potentiates lordosis behavior in hypophysectomized, ovariectomized female rats. Science, N.Y. 182, 1148-1149.

Phillips, R.W., Simmons, V.L. \& Schott, R.G. (1943) Observations on the normal estrous cycle and breeding season in goats and possibilities of modification of the breeding season with gonadotrophic hormones. Am. J. vet. Res. 4, 360-367.

Robinson, J.J., Fraser, C. \& McHattie, I. (1975) The use of progestagens and photoperiodism in improving the reproductive rate of the ewe. Annls Biol. anim. Biochim. Biophys. 15, 345-352.

Robinson, J.J., Fraser, C., McHattie, I. \& Gill, J.C. (1975) The long-term reproductive performance for Finn Landrace and Dorset Horn ewes subjected to photo-stimulation and hormone therapy. Proc. Br. Soc. Anim. Prod. 4, 115-116.

Shelton, M. (1960) Influence of the presence of a male goat on the initiation of estrous cycling and ovulation of Angora does. J. Anim. Sci. 19, 368-375.

Shille, V.M. \& Stabenfeldt, G.H. (1979) Luteal function in the domestic cat during pseudopregnancy and after treatment with prostaglandin $\mathrm{F}_{2 a}$. Biol. Reprod. 21, 1217-1223.

Smith, J.M. (1955) The use of gonadotrophic hormones in goats during the anoestrous period. Vet. Rec. 67, $527-528$.

Stubbings, D.P. (1968) The use of Cronoloneimpregnated pessaries in two goats. Vet. Rec. 83, 3 .

Thorburn, G.D. \& Schneider, W. (1972) The progesterone concentration in the plasma of the goat during the oestrous cycle and pregnancy. $J$. Endocr. $52,23-36$.

Walton, J.S., Cunningham, F.J., Temple, A. \& Bowman, J.C. (1974) Luteinizing hormone and progesterone in the plasma of anoestrous ewes. J. Endocr. 61, lxxxii.

Yeates, N.T.M. (1949) Breeding season of sheep with particular reference to its modification by artificial means using light. J. agric. Sci., Camb. 39, 1-43.

Yuthasastrakosol, P., Palmer, W.M. \& Howland, B.E. (1975) Luteinizing hormone, oestrogen and progesterone levels in peripheral serum of anoestrous and cyclic ewes as determined by radioimmunoassay. J. Reprod. Fert. 43, 57-65. 